Thorax (1976), 31, 107.

\title{
Pulmonary varix
}

\author{
JEROMEC. ARNETT, Jr' and \\ ROBERT M. PAT TON \\ Department of Internal Medicine, Section on Cardiology, Alton Ochsner Medical Foundation \\ and Ochsner Clinic, New Orleans, Louisiana, USA
}

\begin{abstract}
Arnett, J. C., Jr and Patton, R. M. (1976). Thorax, 31, 107-112. Pulmonary varix. Pulmonary varix is a rare disorder which is usually discovered by chance during the third to sixth decade in an asymptomatic patient. The 37th example is reported with a review of the literature. The disorder is possibly congenital and may affect any lobe. Pulmonary angiography is the preferred procedure for diagnosis. If symptoms are present, they can usually be attributed to associated cardiopulmonary disease. Two serious complications have been reported-systematic embolus from a clot in the varix (two cases suspected), and rupture leading to the death of the patient (four cases). A third hazard to the patient is an unnecessary diagnostic thoracotomy. Patients without symptoms should have periodic chest radiographs and those with haemoptysis or systemic embolism should be considered for resection of the varix.
\end{abstract}

Pulmonary varix is a rare vascular abnormality of the lung, only 36 cases having been previously reported (Bartram and Strickland, 1971; Kelvin, Boone, and Peretz, 1972; Papamichael et al., 1972; Owens et al., 1973; Davis et al., 1974; Perrott and Shin, 1974). Since it is usually discovered by chance in an asymptomatic patient, its true incidence is not known. We recently encountered a patient in whom this lesion was first suspected after it was visualized at the time of mediastinoscopy. Ours is only the second patient to have an associated abnormality of the pulmonary arterial tree (Papamichael et al., 1972).

\section{PATIENT SUMMARY}

A 22-year-old black woman was evaluated at Ochsner Clinic because of an abnormal chest radiograph obtained as part of a routine preemployment examination. She had smoked a half pack of cigarettes per day for the previous 10 years and had enjoyed good health in the recent past. The physical examination was normal. No murmur or bruit was heard over the chest or neck. The following studies were normal or negative: complete blood count, erythrocyte sedimentation rate, electrocardiogram, and resting arterial blood gases. The chest radiograph (Fig. 1) revealed a mass in the right paratracheal area and a small right pulmonary artery segment. No 'Present address: Golden Clinic, 1200 Harrison Avenue, Elkins, West Virginia 26241, USA calcifications were seen on planigrams (Fig. 2). A thyroid scan was not done. At mediastinoscopy a soft bulging structure was seen above the area of the azygos vein outside the lung.

For this reason catheterization of the right side of the heart and pulmonary angiography were performed. The cardiac haemodynamics and oxygen saturation were normal. The arterial phase of the angiogram revealed normal flow but disclosed a diminutive hypoplastic right pulmonary artery (Fig. 3). The right hilar mass was distinct from the pulmonary arterial phase. The exact nature of the lesion was readily determined when the mass opacified simultaneously with the pulmonary veins, left atrium, and left ventricle. This occurred before opacification of the aorta which excludes any anomalous supply from the aorta (Bartram and Strickland, 1971) (Fig. 4). Figure 5, a later film taken in rapid sequence, shows complete delineation of the lesion.

\section{COMMENT}

Puchet in 1843 described the first patient with pulmonary varix - a baby who died from intestinal haemorrhage and who also had multiple varices in other organs. The next five cases were diagnosed at necropsy (Hedinger-Basel, 1907; Nauwerck, 1923; Klinck and Hunt, 1933; Neiman, 1934; Jacchia, 1936). Diagnosis by angiography in a living patient was first made by Mouquin et al. 


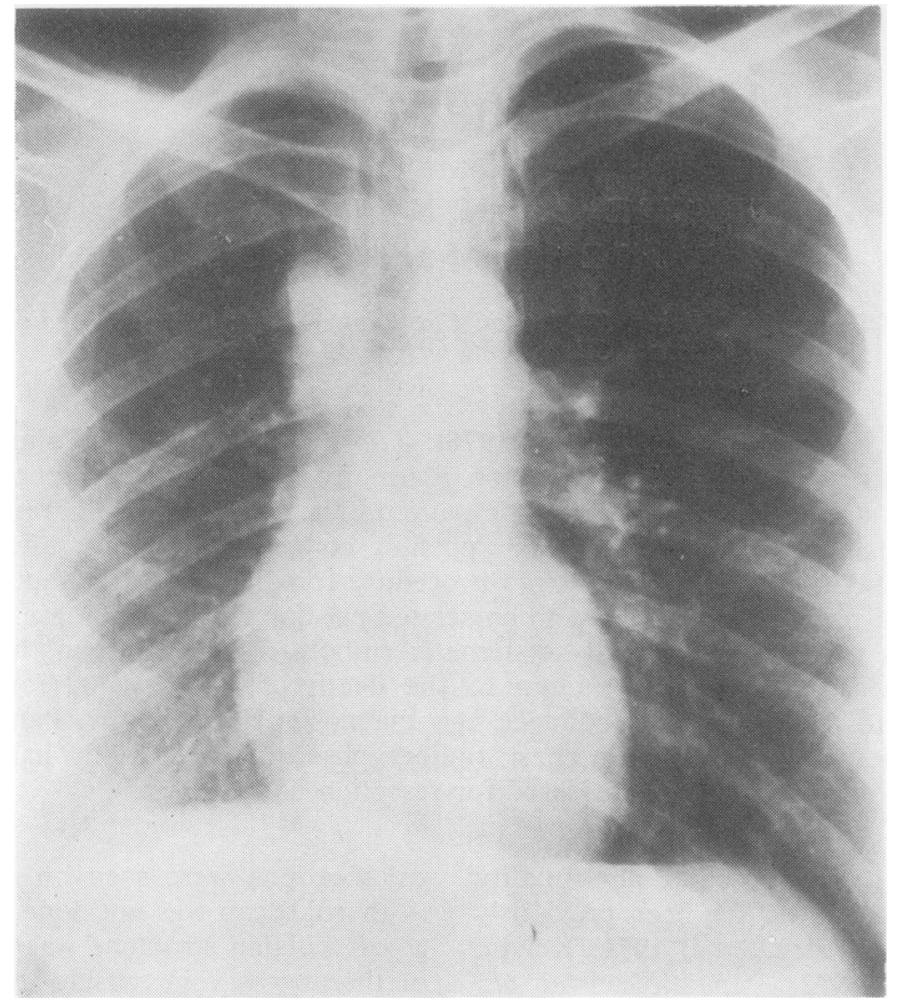

FIG. 1. Postero-anterior view of chest demonstrating mass in the right paratracheal area and a small right pulmonary artery segment.

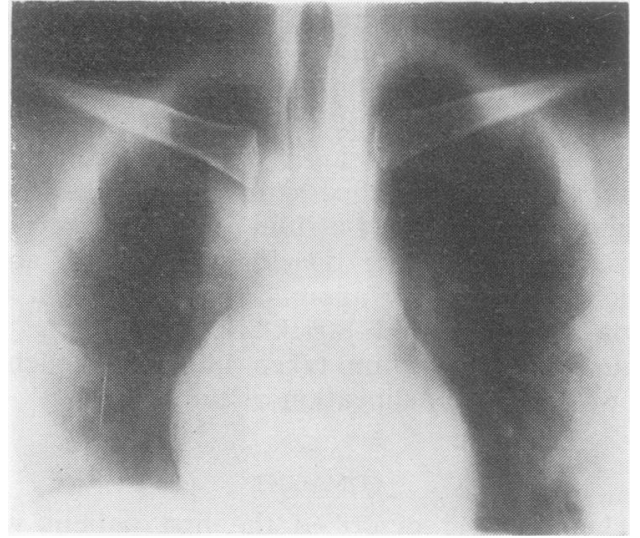

FIG. 2. Tomogram of right paratracheal mass demonstrating absence of calcifications.

(1951) in France. The condition may be congenital in origin, since it can be associated with other congenital anomalies and since it occurs in otherwise healthy children (Klinck and Hunt,
1933; Hagen and Heinz, 1960; Nelson, Hall, and Garcia, 1966; Papamichael et al., 1972). Age at discovery ranges from 7 to 69 years, most cises $\frac{5}{3}$ occurring in the third through the sixth decades (Bartram and Strickland, 1971). Any area of the lung may be involved.

Clinical signs are absent, and symptoms, when 욱 they occur, can almost always be attributed to $D$ associated cardiopulmonary disease. Four patients experienced haemoptysis, but in each one N associated disease might have been responsible (tuberculosis in three, bronchiectasis in one) (Hedinger-Basel, 1907; Nauwerck, 1923; Jacchia, w 1936; Papamichael et al., 1972). Six patients have had mitral valve disease (Case Records of the Massachusetts General Hospital. Case No. 37411, 1951; Hagen and Heinz, 1960; Bryk and Levin, 1965; Hipona and Janshidi, 1967; Kelvin et al., 1972) and increased left atrial pressure may have been an 'aggravating or initiating' factor (Poller $\stackrel{\odot}{\rightarrow}$ and Wholey, 1966; Bartram and Strickland, 1971). Pulmonary venous hypertension was documented in two cases (Bryk and Levin, 1965). Although a 


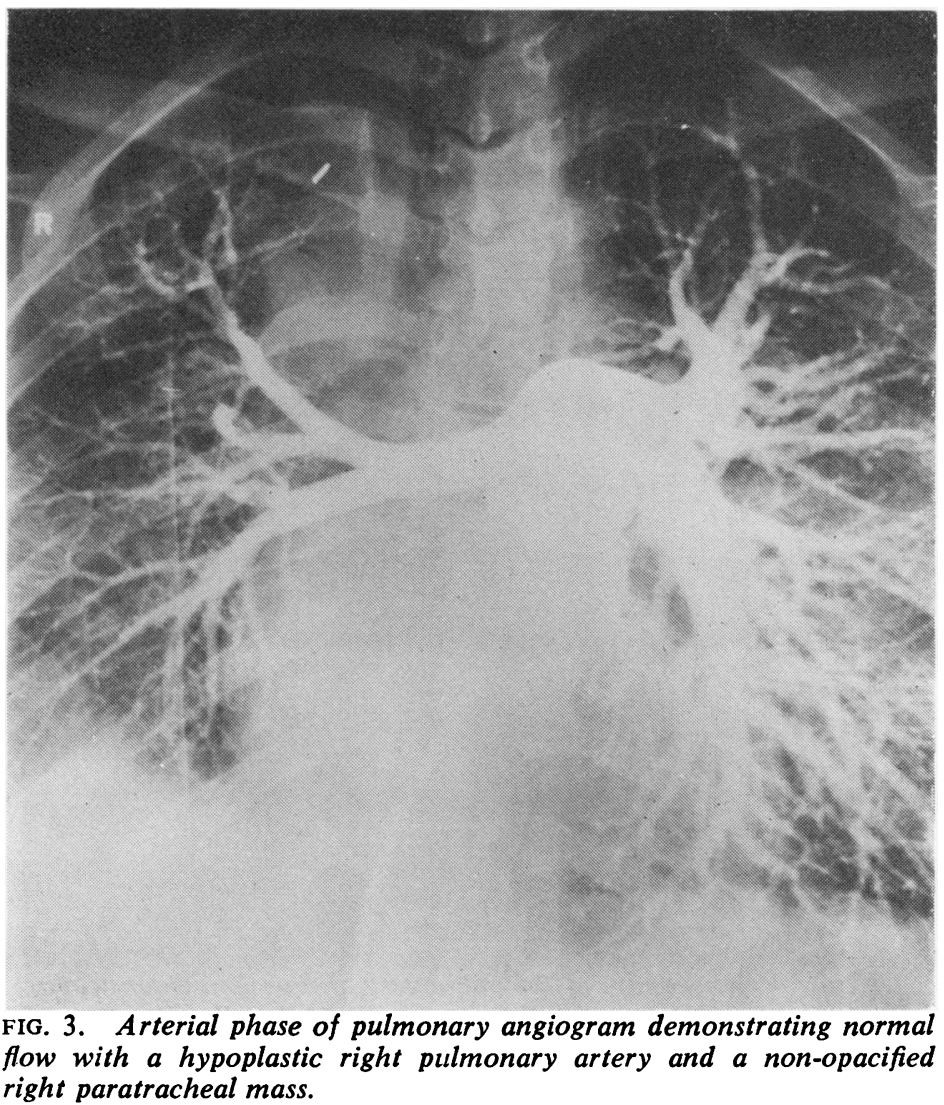

parahilar mass in a patient with severe mitral insufficiency might suggest the possibility of varix, one author found localized dilatation of the central right pulmonary vein in seven of 50 patients with severe mitral insufficiency (Bryk, 1970).

In addition to pulmonary varix our patient had an associated hypoplastic right pulmonary artery (Figs 1 and 3). The only other patient with this abnormality had, in addition, absence of the superior pulmonary vein and eventration of the hemidiaphragm (Papamichael et al., 1972). Other associated congenital abnormalities have included patent ductus arteriosus and ventricular septal defect (Vengsarkar, Kincaid, and Weidman, 1963), double outlet right ventricle (Steinberg, 1967), anomalous venous drainage with pseudocoarctation of the aorta (Bartram and Strickland, 1971), and the Klippel-Trenaunay-Weber syndrome (congenital port wine naevus of the right side of the face, chest, right arm, and left leg, elongation of the right side of the body, and varicose veins of the left leg) (Owens et al., 1973).
The differential diagnosis of an abnormal mass on chest radiography in an asymptomatic patient includes numerous conditions in addition to varix. The more common are pulmonary arteriovenous fistula, tuberculosis, and malignant and fungal diseases. Tomograms may indicate the vascular nature of the lesion, but the differentiation between $\mathrm{A}-\mathrm{V}$ fistula and pulmonary varix is extremely difficult. The presence of clubbing, cyanosis, polycythaemia, telangiectasia, or bullae would suggest the diagnosis of pulmonary A-V fistula rather than pulmonary varix (Hagen and Heinz, 1960).

Pulmonary angiograms are required for definitive diagnosis without resorting to surgery (Good, 1961; Bartram and Strickland, 1971). Bartram and Strickland (1971) reported the angiographic characteristics of a varix to include: (1) a normal arterial flow phase, (2) the varix becoming visible in the venous phase, filling at the same rate as the normal pulmonary vein, (3) the varix draining into the left atrium, (4) delayed emptying of the varix, and, finally, (5) the varicose 


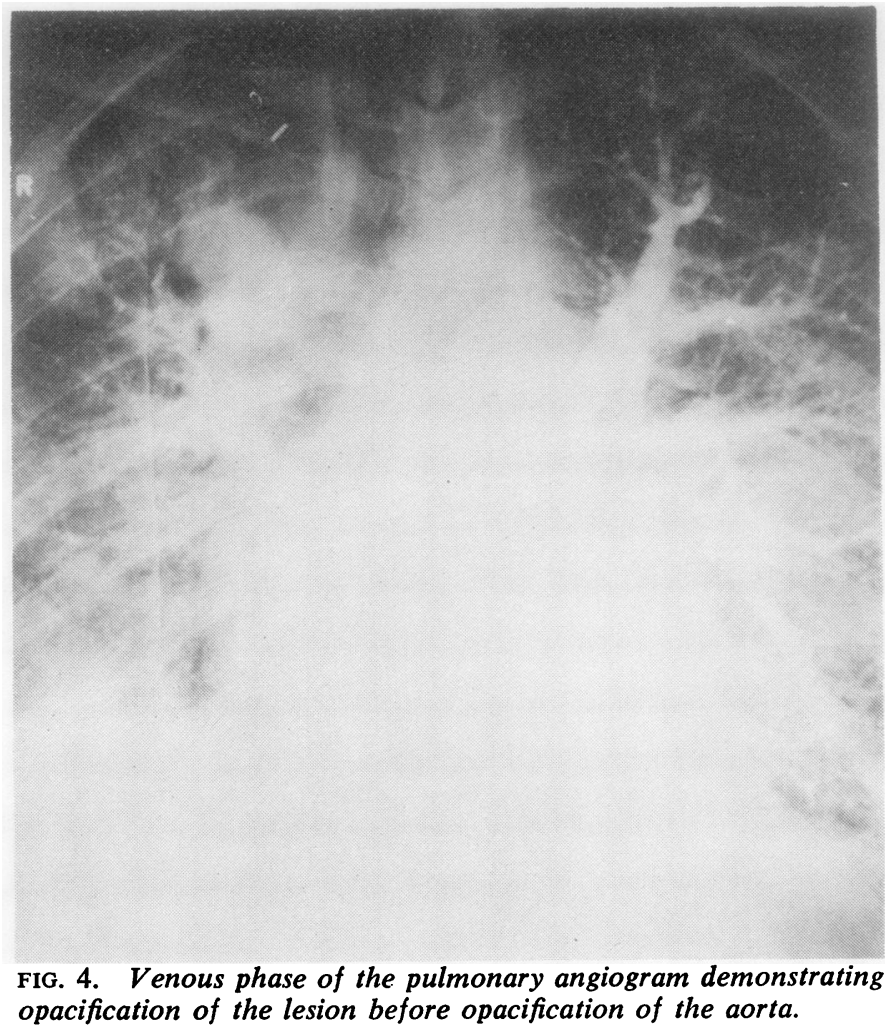

appearance and tortuous course of the vein involving only the proximal portion, the distal branches being normal.

The natural history of the disease has not been well defined. Because of the asymptomatic nature of the lesion, many cases probably remain undetected. If the lesion is not associated with other cardiopulmonary disease, the prognosis is generally good. No change in the size of the lesion on the chest radiograph has been observed in three patients after 10 (Hagen and Heinz, 1960), four (Hipona and Janshidi, 1967), and 15 (Hipona and Janshidi, 1967) years respectively. One patient who had mitral insufficiency was followed up for seven years, the radiographic appearance of the varix enlarging progressively as the mitral disease worsened (Hipona and Janshidi, 1967). Two years after replacement of the mitral valve with a prosthesis, the patient demonstrated a progressive decrease in cardiomegaly and radiographic disappearance of the varix.

If symptoms are present, they usually can be related to associated diseases such as congenital or acquired heart disease or primary pulmonary disease. However, in two cases symptoms may have been secondary to emboli from the varix. Perrett and Fortelius (1961) attributed a transient hemiparesis in their patient to an embolus from a clot which was later demonstrated in the varix. Neiman (1934) ascribed the hemiparesis of his patient to angiospasm, since the symptoms disappeared and no emboli could be found in the cerebral artery at necropsy three months later; however, thrombotic masses and calcium con- 0 cretions were demonstrated in the varix, so that his patient may well have had an embolus. Al- $\frac{7}{O}$ though one cannot be certain that the cerebral symptoms of these patients were related to an $\mathcal{N}$ embolus from the varix, this possibility seems $N$ reasonable from the data available.

A second complication, rupture of the varix, has been uniformly fatal. In two of the four patients this may have been due to erosion of the varix by active pulmonary tuberculosis (Hedinger- of Basel, 1907; Nauwerck, 1923). A third patient had associated severe systemic hypertension o (Klinck and Hunt, 1933). However, rupture of $\underset{\mathbb{D}}{ }$ the varix in the fourth patient remains unex- $\frac{\pi}{\circ}$ plained (Perrett and Fortelius, 1961).

A third hazard to the patient is an unnecessary 


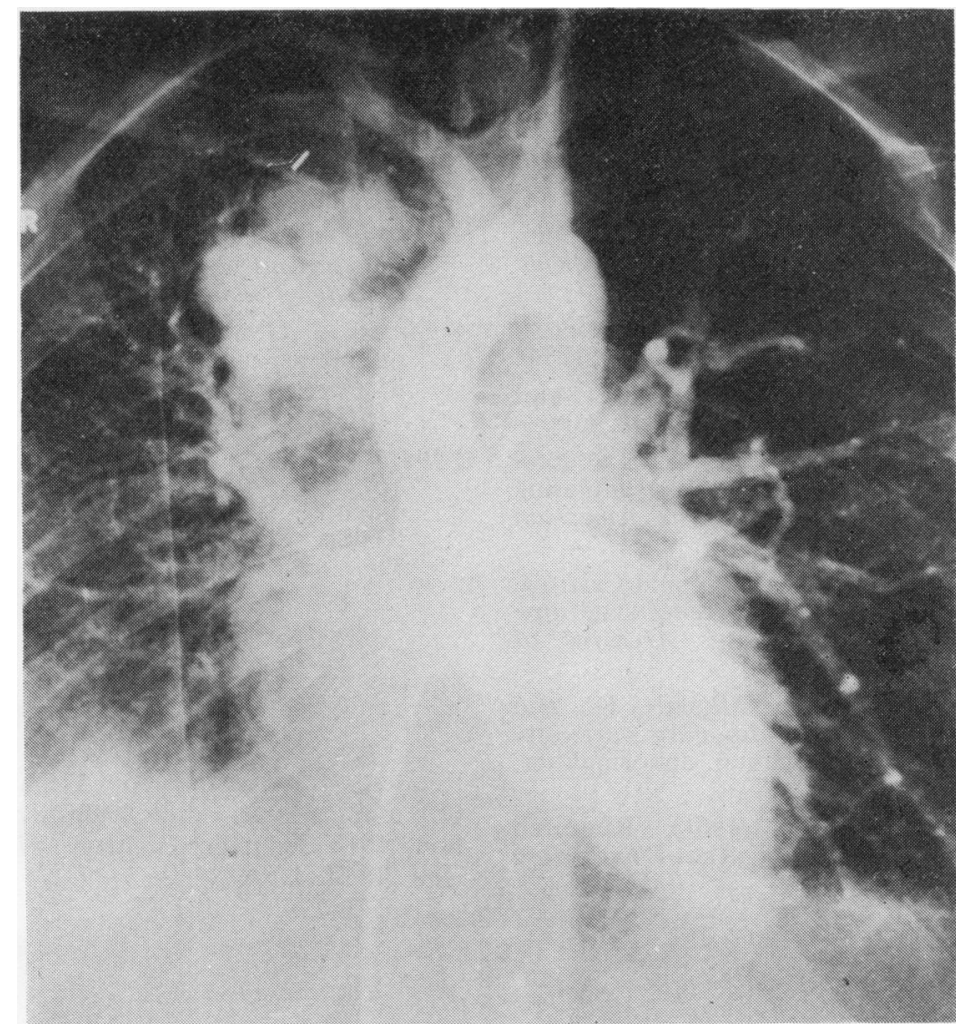

FIG. 5. Venous phase of pulmonary angiogram completely delineating right paratracheal mass.

diagnostic thoracotomy, and four patients have been subjected to this procedure (Good, 1961; Bryk and Levin, 1965; Steinberg, 1967; Davis et al., 1974). Definitive diagnosis should be made by pulmonary angiography.

Due to the small number of reported cases available for analysis, it is impossible to determine the exact complication rate, but prognosis is generally good. Therapy should be individualized depending on the patient's symptoms. Patients without symptoms might best be followed by annual chest radiographs. However, resection of the varix should be seriously considered in any patient who experiences haemoptysis or symptoms suggestive of system:c embolism.

We wish to thank the Department of Medical Communications for their assistance in the preparation of this manuscript.

\section{REFERENCES}

Bartram, E. C. and Strickland, B. (1971). Pulmonary varices. British Journal of Radiology, 44, 927.
Bryk, D. (1970). Dilated right pulmonary veins in mitral insufficiency. Chest, 58, 24. and Levin, E. J. (1965). Pulmonary varicosity. Radiology, 85, 834.

Case Records of the Massachusetts General Hospital (1951). Case No. 37411. New England Journal of Medicine, 245, 575.

Davis, J. E., Golden, M. S., Prince, H. L., Hastings, J. E., and Cheitlin, M. D. (1974). Pulmonary varix: A diagnostic pitfall. Circulation, 49, 1011.

Good, C. A. (1961). Hickey Lecture: Certain vascular abnormalities of the lungs. American Journal of Roentgenology, Radium Therapy and Nuclear Medicine, 85, 1009.

Hagen, H. and Heinz, K. (1960). A varicose node in the lingular branch of the pulmonary vein. Fortschritte auf dem Gebiete der Roentgenstrahlen und der Nuklearmedizin, 93, 151.

Hedinger-Basel (1907) Demonstration eines Lungenvaris. Verhandlungen der deutschen Gesellschaft für Pathologie, 11, 303.

Hipona, F. A. and Janshidi, A. (1967). Observations on the natural history of varicosity of pulmonary veins. Circulation, 35, 471.

Jacchia, P. (1936). Phlebektasie im Lungenparenchym (ein Beitrag zu den isolierten Rundschatten in der Lunge). Acta Radiologica, 17, 74.

Kelvin, F. M., Boone, J. A., and Peretz, D. (1972). 
Pulmonary varix. Journal of the Canadian Association of Radiologists, 23, 227.

Klinck, G. J., Jr., and Hunt, H. D. (1933). Pulmonary varix with spontaneous rupture and death. Report of a case. Archives of Pathology, 15, 227.

Mouquin, M., Hebrard, H., Damasio, R., Jouvet, J., Durand, M., and Piequet, J. (1951). Varice du poumon diagnostiquee par l'angiocardiographie. Bulletin et Mémoires de la Sociéte Médicale des Hôpitaux de Paris, 67, 1091.

Nauwerck, C. (1923). Lungenvarix und Hemoptoe. Münchener medizinische Wochenschrift, 70, 1084.

Neiman, B. H. (1934). Varix of pulmonary vein. American Journal of Roentgenology, 32, 608.

Nelson, W. P., Hall, R. J., and Garcia, E. (1966). Varicosities of the pulmonary veins simulating arteriovenous fistulas. Journal of the American Medical Association, 195, 13.

Owens, D. W., Garcia, E., Pierce, R. R., and Castrow, F. F. (1973). Klippel-Trenaunay-Weber syndrome with pulmonary vein varicosity. Archives of Dermatology, 108, 111.

Papamichael, M. D., Ikkos, D., Alkalais, K., and Yannacopoulos, J. (1972). Pulmonary varicosity associated with other congenital abnormalities. Chest, 62, 107.

Perrett, L. and Fortelius, P. (1961). Ruptured aneurysm of a pulmonary vein. Acta Tuberculosa Scandinavica, 41, 53.
Perrott, W. W. and Shin, M. S. (1974). Pulmonary varix. Journal of Thoracic and Cardiovascular Surgery, 68, 318.

Poller, S. and Wholey, M. H. (1966). Pulmonary varix: Evaluation by selective pulmonary angiography. Radiology, 86, 1078.

Puchet. Quoted by Gimes, B. and Horvath, F. (1958). Uber die Varikosität der Pulmonalvene. Fortschritte auf dem Gebiete der Roentgenstrahlen und der Nuklearmedizin, 89, 545.

Steinberg, I. (1967). Pulmonary varices mistaken for pulmonary and hilar disease. American Journal of Roentgenology, Radium Therapy and Nuclear $\mathrm{\omega}$ Medicine, 101, 947.

Vengsarkar, A. S., Kincaid, O. W., and Weidman, W. H. (1963). Selective angiocardiography in diagnosis of varicosity of the pulmonary veins. Report of a case. American Heart Journal, 66, 396.

Requests for reprints to: Department of Medical Communications, Alton Ochsner Medical Foundation, 1514 Jefferson Highway, New Orleans, Louisiana 70121, USA. 